\title{
MPPT Design Using PSO Technique for Photovoltaic System Control Comparing to Fuzzy Logic and P\&O Controllers
}

\author{
0. Ben Belghith1, L. Sbita1, F. Bettaher ${ }^{2}$ \\ ${ }^{1}$ Research Unit of Photovoltaic, Wind and Geothermal Systems, National Engineering School of Gabes (ENIG), University of Gabes, Rue \\ Omar Ibn-Elkhattab, Zrig, Gabes, Tunisia \\ ${ }^{2}$ Hatem Bettaher Research Unit of Computing, Networks, Communication Systems and Mathematics, IResCoMath, Higher Institute of \\ Informatics and Multimedia of Gabes (ISIMG), University of Gabes, Gabes, Tunisia \\ Email: oussama.benbelghith@gmail.com, lassaad.sbita@enig.rnu.tn, fbettaha@gmail.com
}

How to cite this paper: Belghith, O.B., Sbita, L. and Bettaher, F. (2016) MPPT Design Using PSO Technique for Photovoltaic System Control Comparing to Fuzzy Logic and P\&O Controllers. Energy and Power Engineering, 8, 349-366. http://dx.doi.org/10.4236/epe.2016.811031

Received: September 28, 2016 Accepted: November 27, 2016

Published: November 30, 2016

Copyright $\odot 2016$ by authors and Scientific Research Publishing Inc. This work is licensed under the Creative Commons Attribution International License (CC BY 4.0).

http://creativecommons.org/licenses/by/4.0/ (c) (i) Open Access

\begin{abstract}
The Maximum Power Point Tracker (MPPT) is the optimum operating point of a photovoltaic module. It plays a very important role to obtain the maximum power of a solar panel as it allows an optimal use of a photovoltaic system, regardless of irradiation and temperature variations. In this research, we present a novel technique to improve the control's performances optimization of the system consisting of a photovoltaic panel, a buck converter and a load. Simulations of different parts of the system are developed under Matlab/Simulink, thus allowing a comparison between the performances of the three studied controllers: "Fuzzy TS", "P\&O" and "PSO". The three algorithms of MPPT associated with these techniques are tested in different meteorological conditions. The obtained results, in different operating conditions, reveal a clear improvement of controlling performances of MPPT of a photovoltaic system when the PSO tracking technique is used.
\end{abstract}

\section{Keywords}

Photovoltaic System, MPPT Controller, Buck Converter, Perturb and Observe

"P\&O”, Fuzzy Logic "Fuzzy TS", Particle Swarm Optimization "PSO"

\section{Introduction}

The photovoltaic solar energy deriving from the direct transformation of a part of solar irradiation into electric energy faces, inter alia, a maximization problem of power transfer of the photovoltaic generator (PVG) to the load. This is due to the non-linear feature of the electric characteristics I-V (Current-Voltage) of photovoltaic cells [1]. 
These characteristics depend on the illumination level, the temperature of the cell and the load. In order to increase the output power of a photovoltaic energy system, it is indispensable to make the photovoltaic panel operate at Maximum Power Point (MPP), to extract, at every moment, the maximum of power available at the PVG boundaries. The technique commonly used is to insert an adapting interface between the PVG and the load. This adapting interface consists of a static converter driven by Pulse Width Modulation (PWM) [2] [3]. The majority of articles dealing with control algorithms (MPPT) are based on the incremental conductance method (IncCon) or on Perturb and Observe (P\&O) [4] [5] [6]. The fuzzy logic controller type Mamdani, as well, has been studied [7] [8]. In these last years, the analysis and synthesis of non-linear systems, described by fuzzy models type Takagi-Sugeno (TS), have also been widely studied in the literature [9] [10].

In this work, we present a robust technique which permits to track the MMP of the PV panel system, thanks to the controller using PSO. This control technique reduces the calculating time and keeps a good precision. In addition, it can be implemented in a low-cost microcontroller [11] [12]. This controller "PSO" developed as such, will be subsequently used and compared to other classic tracking algorithms.

This paper is organized as follows. We present, in Section 2, the working environment and the electric modelling of the studied system, as well as the description of the developed algorithms for tracking techniques of MPP: "P\&O", "Fuzzy TS" and "PSO". Section 3 is dedicated to the presentation of models under Matlab/Simulink version 2014 associated with different components of the tested conversion chain. In Section 4, we show and interpret simulation's results concerning the PV system behaviors under the effect of one of the three controllers "P\&O", "Fuzzy TS" or "PSO" under different irradiation changes $S$ and temperature T. We present also the evaluation of the performances of each of the studied MPP controllers. Finally, we finish our contribution with a summary of our research works.

\section{PV Conversion Chain}

As the PV conversion chain illustrates in Figure 1, MPP is reached through controlling the DC-DC converter with a system using a MPPT controller. The strategy of the MPPT controller allows to optimize the transfer of power from the PV panel to the load.

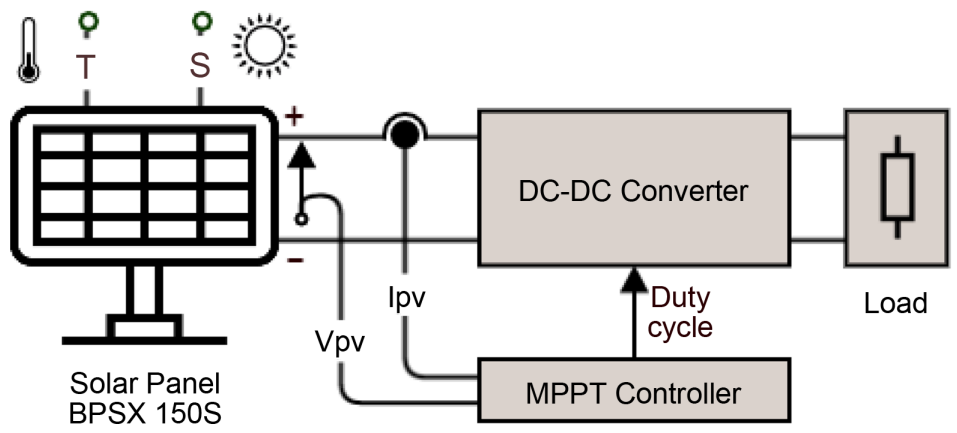

Figure 1. Elementary chain of photovoltaic conversion. 
The studied PV panel (Figure 1) is BPSX 150S type [13]. Table 1 sums up the electric characteristics of the PV panel in the Standard Test Conditions (STC): $1000 \mathrm{~W} / \mathrm{m}^{2}$, $25^{\circ} \mathrm{C}$ and AM 1.5. We will present the Matlab-Simulink model which is based on these characteristic values.

\subsection{Electric Modeling of the Studied System}

\subsubsection{PV Panel Model}

In order to model our PV panel, we start with a simple model which is one of a PV elementary cell. The configuration that Figure 2 presents is the most common equivalent schema of a solar cell. It is composed of a source of variable current $I_{p}$, connected in parallel with a diode $\mathrm{D}$, characterizing the junction of semi-conductors which make the solar cell, and a parallel resistance $R_{p}$. To this assembly, another resistance $R_{s}$ is added in series.

The model of a PVG issues from this schema, defined by the following equations [1]:

$$
\begin{gathered}
I=\left(I_{p v, n}+K_{i} \Delta T\right) \frac{S}{S_{n}}-\left[\exp \left(\frac{q\left(V+R_{s} I\right)}{a N_{s} K T}\right)-1\right]-\frac{V+R_{s} I}{R_{p}} . \\
I_{0}=\frac{I_{s c, n}+K_{i} \Delta T}{\exp \left(\frac{V_{o c, n}+K_{v} \Delta T}{a V_{t}}\right)} .
\end{gathered}
$$

With:

- a: Ideality factor of the solar cell.

- $\Delta T=T-T_{n}$ (Kelvin), $T$ : Real temperature of the cells and $T_{n}$ : nominal temperature of the cells in the Standard Test Conditions (STC): $1000 \mathrm{~W} / \mathrm{m}^{2}, 25^{\circ} \mathrm{C}$ and AM 1.5.

Table 1. PV panel parameters (type: BPSX 150S).

\begin{tabular}{cc}
\hline Parameters & Values \\
\hline Pmax: maximum power & $150 \mathrm{~W}$ \\
Imp: maximum power current & $4.35 \mathrm{~A}$ \\
Vmp: maximum power voltage & $34.5 \mathrm{~V}$ \\
Ns: number of series cells & 36 \\
Isc: short circuit current & $4.75 \mathrm{~A}$ \\
Voc: open circuit voltage & $43.5 \mathrm{~V}$ \\
\hline
\end{tabular}

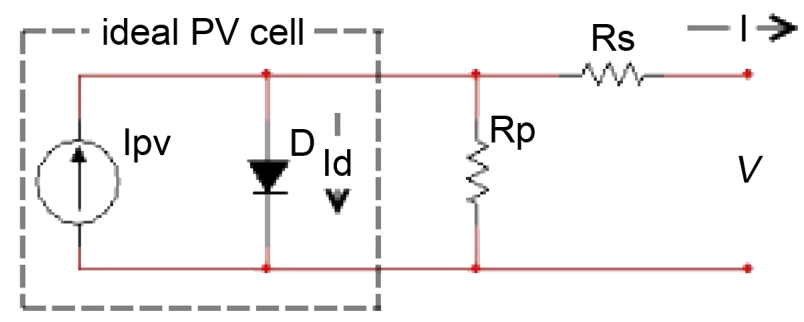

Figure 2. Equivalent electric circuit of solar cell. 
- $S$ : Real Irradiation $\left(\mathrm{W} / \mathrm{m}^{2}\right)$.

- $S_{n}$ : Nominal Irradiation in the Standard Test Conditions $\left(\mathrm{W} / \mathrm{m}^{2}\right)$.

- $I_{0}$ : Diode reverse saturation current (A).

- $I_{p \vee, n}$ : Current measured under Standard Test Conditions (A).

- I, V: PVG current (A) and voltage (V).

- $I_{s c, n}$ and $V_{o c, n}$ : Short circuit current (A) and Open circuit voltage (V) measured under Standard Test Conditions.

- $V_{t}=N_{s} K T / q$ : Thermal voltage.

- $N_{s}$ : Number of series-connected cells.

- $K$ : Boltzmann constant (1.38 $10-23 \mathrm{~J} / \mathrm{K})$.

- $K_{v}$ : temperature coefficient of the open circuit voltage $\left(=80 \pm 10 \mathrm{mV} /{ }^{\circ} \mathrm{C}\right)$.

- $K_{i}$ : temperature coefficient of the short circuit current $(=0.065 \pm 0.015) \% /{ }^{\circ} \mathrm{C}$.

- $q$ : Electron charge $(1.610-19 \mathrm{C})$.

- $R_{s}, R_{p}$ : Series resistance $(=0.2365 \Omega)$ and parallel resistance $(=415.405 \Omega)$ respectively.

\subsubsection{Static Converter Type Buck}

In our research, the suggested system in Figure 1 contains a power converter DC-DC type Buck, driven by using the Pulse Width Modulation principle. This converter is modeled by the equivalent electric schema in Figure 3.

As far as the simulations of the studied converter are concerned, the parameters we have used are: the resistance of the load being $R_{c}=3 \Omega$, the capacitance of the capacitor being $C=4.7 \mu \mathrm{F}$, the inductance of the inductor being $L=2 \mathrm{mH}$, D being freewheeling diode and $\mathrm{T}$ being a transistor type MOSFET. During the operation in continuous mode of this buck converter, the average values of the output voltage $V_{s}$ and input voltage $V_{e}$ are proportional as follows:

$$
V_{s}=V_{e}
$$

The proportionality coefficient $\alpha$, being the duty cycle of values ranging from 0 to 1 . In this present case, we use an average model of a buck converter, that is, $V_{D} \approx \alpha V_{e}$. Therefore, this converter will be described by the following equations [14]:

$$
\begin{aligned}
& C \frac{\mathrm{d} V_{s}}{\mathrm{~d} t}=i_{L}-\frac{V_{s}}{R_{s}} . \\
& L \frac{\mathrm{d} i_{L}}{\mathrm{~d} t}=\alpha V_{e}-V_{s} .
\end{aligned}
$$

To limit the ripples of the current and voltage at the level of the load, the LC cell,

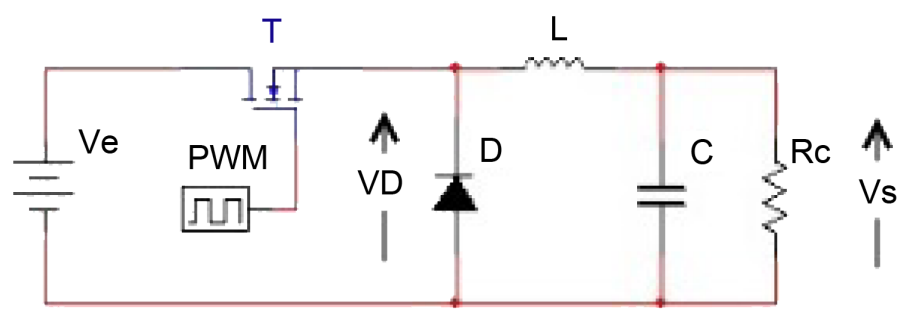

Figure 3. Equivalent electric circuit of buck converter. 
connected to the equivalent circuit in Figure 3, constitutes a low-pass filter. To size this filter, we determine the minimal values of the inductance $L$ and the capacitance $C$, bearing in mind the following constraints, studied by a number of authors [15]:

- The current through the inductormust be in a reasonable range in all load conditions as the converter operates in continuous mode.

- The maximum output voltage ripple must not exceed $5 \%$ of the output voltage $V_{s}$.

Considering these constraints, the low-pass filter LC must respond to all the conditions of the following relations, where $f_{c}$ corresponds to the PWM switching frequency:

$$
\begin{aligned}
& L \geq \frac{d V_{e}}{\Delta I_{s} f_{c}} \alpha(1-\alpha) . \\
& C \geq \frac{(1-\alpha)}{8 L f_{c}^{2}}\left(\frac{V_{s}}{\Delta V_{s}}\right) .
\end{aligned}
$$

According to the values in Table 2 and the conditions for $C$ and $L$, we consider the optimum values, as follows: inductor $(L \geq 1.6 \mathrm{mH})$ and capacitor $(C \geq 2.7 \mu \mathrm{F})$.

\subsection{MPPT Tracking Controllers}

The power chain supply a DC load by the PVG through a static converter (SC) driven by a MPPT controller represented in Figure 4 and based on one of the algorithms "Fuzzy TS", "P\&O" or "PSO". The MPPT controller adjusts the duty cycle of the SC in such a way that the power provided by the PVG is maximum at its boundaries.

Table 2. Relative parameters of low-pass LC filter design.

\begin{tabular}{cc}
\hline Parameters & Value \\
\hline Ve: Input Voltage & $24 \mathrm{~V}$ \\
Vsmax: Output maximum voltage & $23.4 \mathrm{~V}$ \\
Ismax: Output maximum current & $5 \mathrm{~A}$ \\
fc: PWM switching frequency & $15 \mathrm{KHz}$ \\
$\Delta$ Vs and $\Delta$ Is: Maximum ripple of output voltage and output output current respectively & $5 \%$ of Vs and Is \\
$\alpha$ : Duty cycle & 0.5 \\
\hline
\end{tabular}

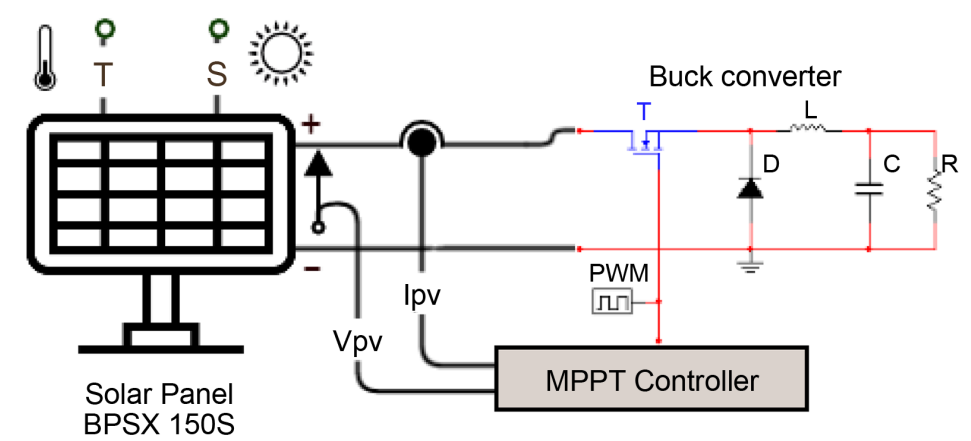

Figure 4. PV system with buck converter driven by MPPT. 


\subsubsection{P\&O Controller "Perturb and Observ" [16]}

The algorithm "P\&O" is a MPPT controller based on the voltage perturbation Vpv, by increasing or decreasing a low amplitude around its initial value.

This perturbation directly affects the duty cycle of the signal which controls the DC-DC converter. This perturbation is followed by the observation of its impact on the output power of the PV panel with the aim of eventually correcting this duty cycle.

Figure 5 presents the flow chart which describes the algorithm providing this controller called "P\&O".

Despite of its performance, this technique presents some problems related to oscillations around the MPP that it generates in steady state as the research procedure of the MPP must be repeated periodically, forcing the system to oscillate permanently around the MPP.

These oscillations can be minimized by reducing the variable value of the perturbation. Yet, a low increment value slows down the searching of the MPP. As such, it is necessary to find a compromise between precision and fastness, which makes this controller quite hard to optimize.

\subsubsection{Fuzzy Controller Type Takagi-Sugeno [17]}

The fuzzy models Takagi-Sugeno are renowned for being an efficient technique to represent a non-linear system with fuzzy sets and fuzzy reasoning. Like the Mamdani model, this type of model builds using a base of rules of the type "If ... then ..." where

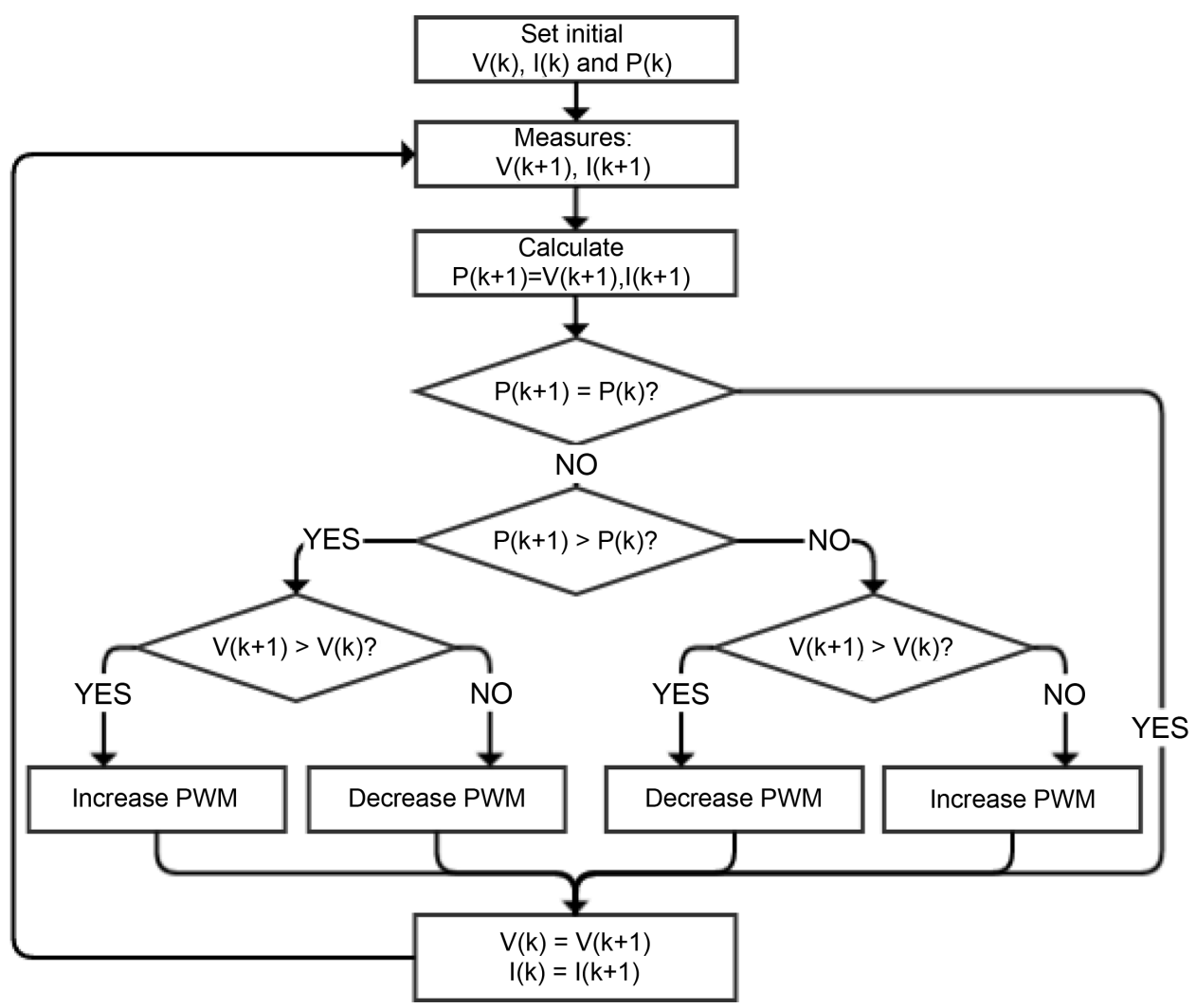

Figure 5. Flow chart of $\mathrm{P} \& \mathrm{O}$ controller. 
if the antecedent is always linguistically expressed, the consequent uses numerical variables rather than linguistic variables. The consequent may be expressed, for instance, as a constant, a polynome or, more generally, as a function or a differential equation depending on variables associated with the antecedent. Generally, the model type Takagi-Sugeno is based on a collection of rules $R i$ of the type:

$$
R i \text { : If ( } E \text { est } A i) \text { And }(\Delta E \text { est } B i) \text { Then } y i=f i(E, \Delta E) \text { for } i=1,2, \cdots, n
$$

where Ride notes the ith rule of the model and $n$ the number of fuzzy rules that the base of rules contains. $E$ and $\Delta E$ are the input variables $x$, called antecedents, and $y$ is the output variable, called consequent.

$A i$ and $B i$ are fuzzy sets of the antecedent of the nth rule. These fuzzy rules are defined by membership functions $\mu_{A i}(E)$ or $\mu_{B i}(\Delta E)$ belonging to the interval $[0,1] . \mu_{A i}(E)$ or $\mu_{B i}(\Delta E)$ symbolize the value of membership functions of the input $E$ or the input $\Delta E$ respectively to the fuzzy set $A$ i or $B i$.

In the case where the consequents $y i=f i(E, \Delta E)$ take the form of a constant, which corresponds to our study case $(y i=\Delta \alpha)$, the model is called singleton or zero order.

The suggested fuzzy logic controller to optimize the system, is represented in Figure 6. It receives as input the error and the error variation of the system $(E(k), \Delta E(k))$. In the output, the variation of the duty cycle is generated $\Delta \alpha$ driving the DC-DC converter. This controller can be split in three principal modules:

- Input: Fuzzification. It associates a membership degree ranging from 0 and 1 with each of the real inputs.

- Inference engine: it is associated to the base of rules type: "If ... then ...".

- Output: Defuzzification. It permits the transformation of the membership degrees of fuzzy sets into numerical values.

Our fuzzy controller presented in Figure 7 is characterized by:

- Two inputs: error $E$ and its variation $\Delta E$ and one output $\Delta \alpha$.

- Scaling factors $K_{1}$ and $K_{2}$ (from -1 to 1 ) for the normalization of inputs associated with the error and its variation.

- The universe of discourse divided into five classes, further described below, for the input and output variables.

- Triangular and trapezoidal membership functions.

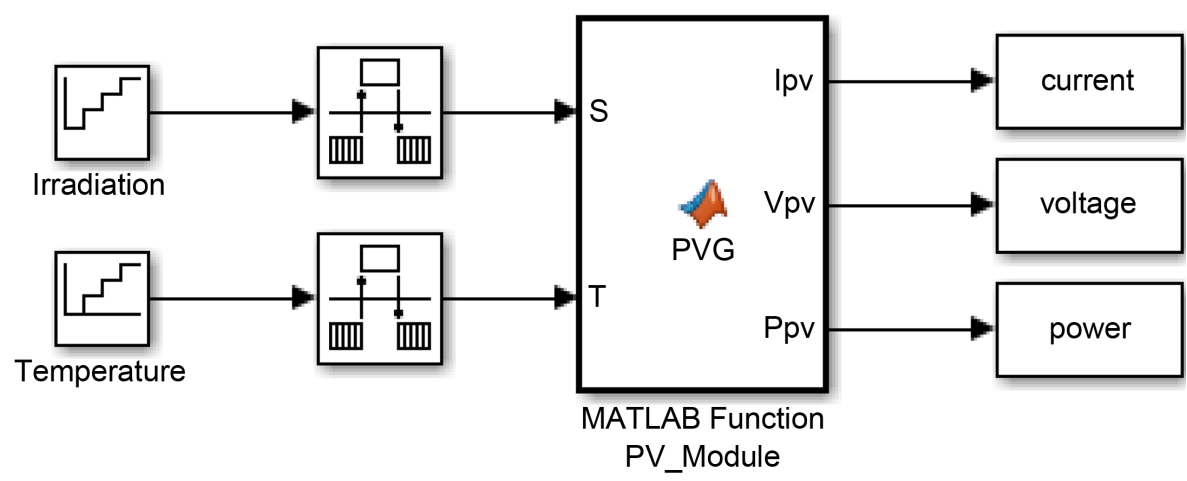

Figure 6. Bloc diagram of PV module. 


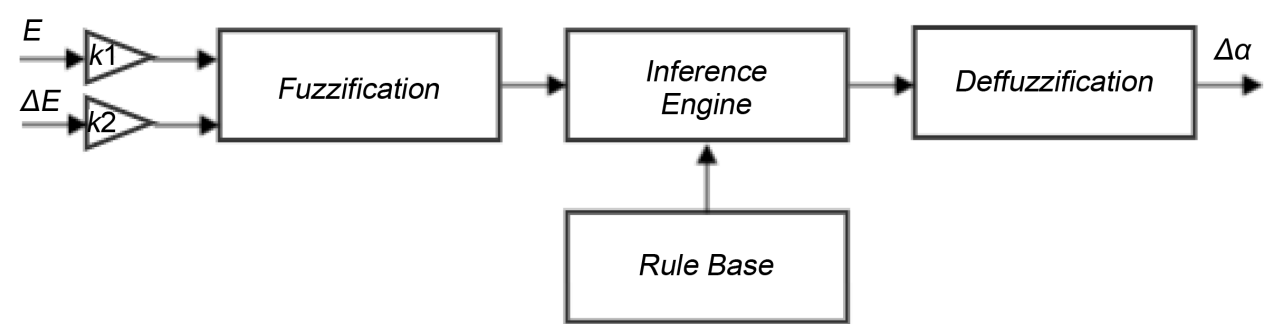

Figure 7. Fuzzy controller structure.

- Involvement of Takagi-Sugeno for inference.

- The weighted average method for the calculation of the output.

The two input variables $E$ and $\Delta E$ are defined by the two following expressions:

$$
\begin{gathered}
E=\frac{\Delta P_{p v}}{\Delta V_{p v}}=\frac{P_{p v}(t)-P_{p v}(t-1)}{V_{p v}(t)-V_{p v}(t-1)} . \\
\Delta E=E(t)-E(t-1) .
\end{gathered}
$$

With:

$P_{p v}(t)$ :The instantaneous power generated by PVG (in W).

$V_{p v}(t)$ : The instantaneous voltage at boundaries of PVG (in V).

The controller output $\Delta \alpha$ is defined by the control law which depends on the error $E$ and its $\Delta E$ as follows:

$$
\Delta \alpha=f(E, \Delta E) .
$$

And the duty cycle $\alpha$, which drives the DC-DC converter, is expressed by:

$$
\alpha(t)=\alpha(t-1)+\Delta \alpha .
$$

The big advantage of the Takagi-Sugeno technique is that it permits to simplify the aggregation calculation, so that we can not only obtain a simple solution more rapidly but also alleviate the global calculation mechanism significantly.

In the Takagi-Sugeno modelling, the final output is equal to the weighted average of the output of each rule. This average is given by the following expression:

$$
C G_{\text {Sugeno }}=\frac{\sum_{i=1}^{n} z_{i} w_{i}}{\sum_{i=1}^{n} w_{i}} .
$$

where $Z_{i}$ is the output level of each rule $R_{i}$ and $w_{i}$ is the membership calculated by the following equation:

$$
w_{i}=\mu_{A i}(E) \cdot \mu_{B i}(\Delta E) .
$$

The rules base is summarized in Table 3. In our system case, the universe of discourse is divided into five classes NL, NS, ZO, PS and PL, for the input and output variables as follows: NL for negative large, NS for negative small, ZO for zero, PS for positive small and PL for positive large.

The membership functions used in the case of our fuzzy controller are of triangular and trapezoidal types for the input, but of singleton type for the output. 
Table 3. Fuzzy rules base.

\begin{tabular}{cccccc}
\hline \multicolumn{1}{c}{$E$} & $N L$ & $N S$ & $Z O$ & $P S$ & $P L$ \\
\hline$N L$ & $P L$ & $P L$ & $P L$ & $P S$ & $Z O$ \\
$N S$ & $P L$ & $P L$ & $P S$ & $Z O$ & $N S$ \\
$Z O$ & $P L$ & $P S$ & $Z O$ & $N S$ & $N L$ \\
$P S$ & $P S$ & $Z O$ & $N S$ & $N L$ & $N L$ \\
$P L$ & $Z O$ & $N S$ & $N L$ & $N L$ & $N L$ \\
\hline
\end{tabular}

\subsubsection{PSO Controller "Particle Swarm Optimisation"}

\section{1) The basic PSO algorithm [14] [15]}

PSO technique [14] [15] is a robust stochastic optimization technique based on the movement and intelligence of swarms. It applies the concept of social interaction to problem solving. It uses a number of agents (particles) that constitute a swarm moving around in the search space looking for the best solution.

Each particle keeps track of its coordinates in the solution space which are associated with the best solution (fitness) that has achieved so far by that particle. This value is called personal best, $P_{\text {best }}$.

Another best value that is tracked by the PSO is the best value obtained so far by any particle in the neighborhood of that particle. This value is called $G_{b e s t}$.

During the optimization process, the particles take up the objective function's values, while their $G_{b e s t}$ and $P_{\text {besti }}$ are saved. The basic PSO algorithm which determines the next velocity and position of the candidate solution can be given mathematically as:

$$
\begin{gathered}
v_{i}^{k+1}=w \times v_{i}^{k}+r_{1} \times c_{1} \times\left(P_{\text {besti }}-x_{i}^{k}\right)+r_{2} \times c_{2} \times\left(G_{\text {best }}-x_{i}^{k}\right) \\
x_{i}^{k+1}=x_{i}^{k}+v_{i}^{k+1}
\end{gathered}
$$

In the afore mentioned expression, $i$ represents the variable of the optimization vector, $k$ is the number of iterations, $v_{i}^{k}$ and $x_{i}^{k}$ respectively the velocity and position of the ith variable within $k$ iterations, the parameter $w$ is known as inertia that maintains a balance between the local and global search. $c_{1}$ and $c_{2}$ are acceleration constants. $r_{1}$ and $r_{2}$ are two generated random numbers which are uniformly distributed in the interval $[-1,1]$.

The variable $P_{\text {besti }}$ records the best position affected by the $i t h$ particle up to the exact time of measurement. The following equation indicates that this position is only recorded as $P_{\text {best }}$ if the condition stated below is satisfied.

$$
P_{\text {besti }}=x_{i}^{k} \text { if } f i t\left(x_{i}^{k}\right) \geq f i t\left(P_{i}\right)
$$

\section{2) Configuration of PSO parameters}

The search space of the problem in which each position represents an Output Voltage value as a solution to the MPPT problem. The evaluation of the particles is based on the Output Power of the PV panel respective to the final voltage value which is indicated by fit as the fitness evaluator for the particles. The following equation shows the 
position matrix of the $n$ particles which represents $n$ solutions to the MPPT problem.

$$
x_{i}^{k}=\left[x_{1}^{k}, x_{2}^{k}, x_{3}^{k}, \cdots, x_{i}^{k}, \cdots, x_{(n-1)}^{k}, x_{n}^{k}\right]
$$

where $x_{i}^{k}$ is the position of $\dot{t}$ th particle at $k$ th iteration.

Therefore, the algorithm must be initialized when the following equation is satisfied.

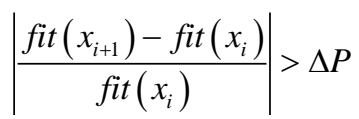

The PSO algorithm implementation process in this paper is as follow:

i) Initialize the size of swarm, dimension of search space, maximum number of iterations, and the PSO constants $W, c_{1}$ and $c_{2}$. Define the random numbers $r_{1}$ and $r_{2}$.

ii) Find out the current fitness of each particle in the population.

iii) Attribute the particles with random initial positions and velocities.

iv) Evaluate fitness value of each particle.

v) Calculate the global best fitness value: current global best fitness $=\min$ (local best fitness).

vi) Update the particle velocity and position for next iteration. Find out the current fitness of each particle: If current fitness $<$ local best fitness, set local best fitness $=$ current fitness.

vii) Determinate the current global best fitness (current global best fitness $=\min$ (local best fitness)): If current global best fitness < global best fitness, then global best fitness $=$ current global best fitness. The position corresponding to global best fitness is assigned to $G_{b e s t}$.

viii) Repeat Steps 6 and 7 until achieved the maximum number of iterations or there is no improvement of the global best fitness value.

ix) Terminate the iterative algorithm when the criterion is reached.

\section{Conversion Chain Modelling under Matlab/Simulink}

In this part, we present the models used to simulate the different components of the PV conversion chain by working in the Matlab/Simulink environment.

\subsection{Photovoltaic Panel}

The PV panel model as presented in section 2.1.1 is resolved by Newton-Raphson method [13].

The associated program is implemented in the block diagram in Simulink presented in Figure 6. This program is translated with the aid of an Matlab function.

\subsection{Buck Converter}

The block diagram achieved under Simulink, is presented in Figure 8. It corresponds to the model of the buck converter integrated in the PV conversion chain.

\subsection{MPPT Controller Type "P\&O"}

In the first phase, we implement under Simulink the complete diagram of the PV sys- 
tem with the "P\&O" controller model as illustrated in Figure 9.

\subsection{MPPT Controller Type Fuzzy Takagi-Sugeno}

In the second phase, the fuzzy controller, too, is implemented under Simulink thanks to an S-function of Matlab, as shown in Figure 10.

\subsection{MPPT Controller Type PSO}

In the last phase, the technique PSO, as well, is implemented under Simulink. The complete diagram of the PV system is presented in Figure 11.

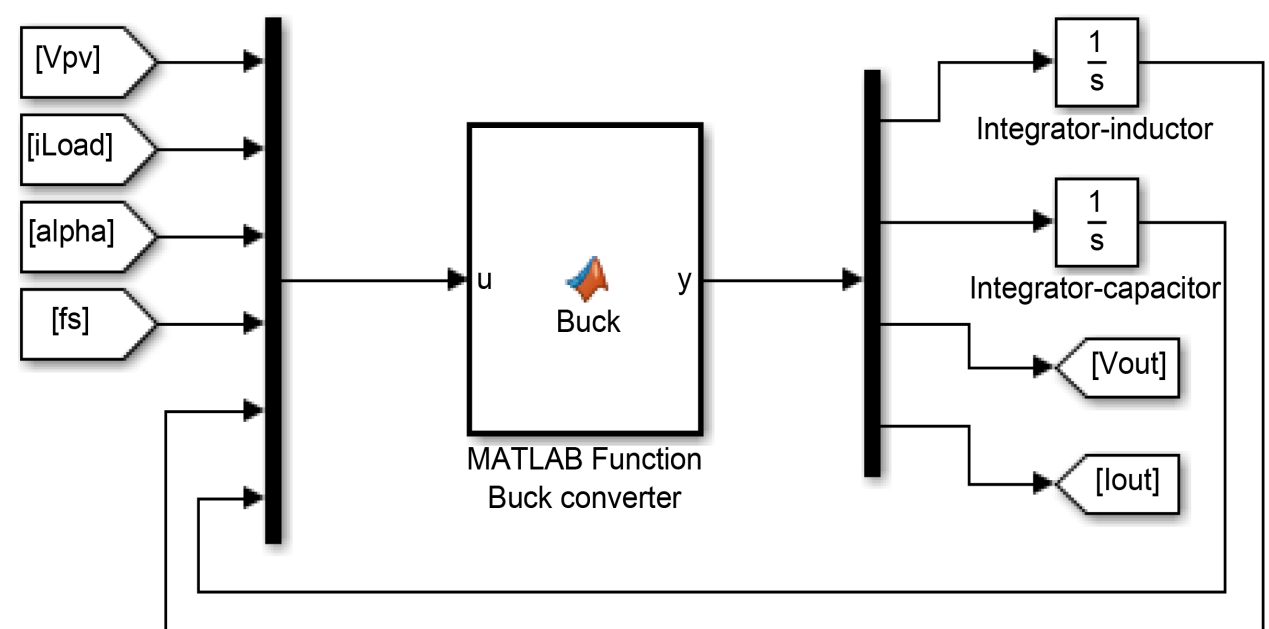

Figure 8. Buck converter diagram.

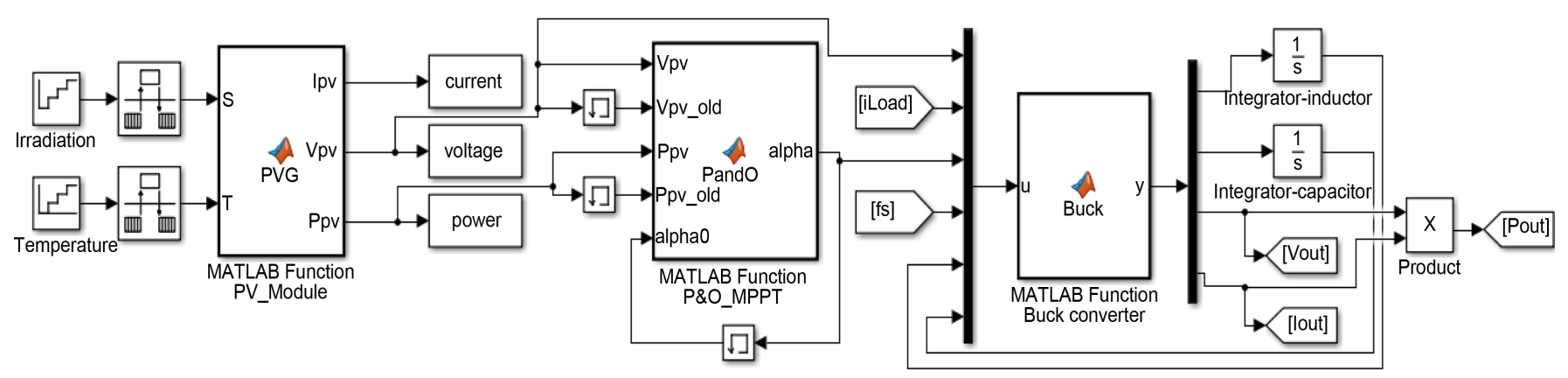

Figure 9. PV system diagram with $\mathrm{P} \& \mathrm{O}$ controller.

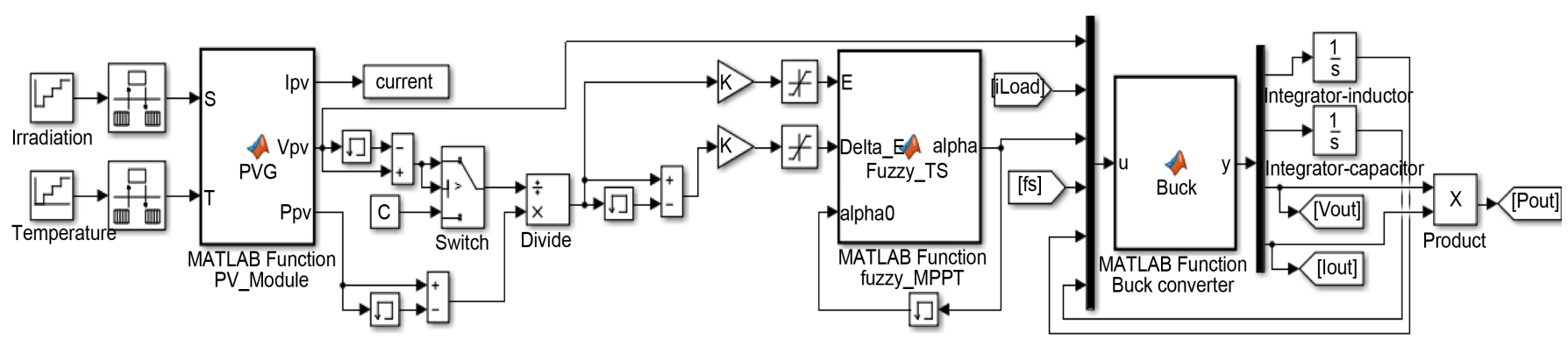

Figure 10. PV system diagram with fuzzy takagi-sugeno controller. 


\section{Analysis of Simulation Results}

\subsection{Behavior of the System}

\subsubsection{Behavior vis-à-vis Variations of $G$ and $T$ of the System under the "P\&O", "Fuzzy Ts" And "PSO" Controllers}

In this section, we compare through simulations, the convergence towards the MPP concerning the output power of the studied PV system by using one of the three controllers "P\&O", "Fuzzy TS" and "PSO".

A temperature $T$ set at $25^{\circ} \mathrm{C}$, while the irradiation $S$ is rapidly variable taking the form of stairs with rising edges within a short time span.

Evaluation: regarding the afore mentioned variations and the results in Figure 12, we deduce the following observations and interpretations concerning the PV system behavior vis-à-vis the three MPPT controllers "P\&O", "Fuzzy TS" and "PSO":

- For these three controllers, we note the impact of the increase of the power generated by the PV system due to the increase of irradiation $S$ when the temperature is constant.

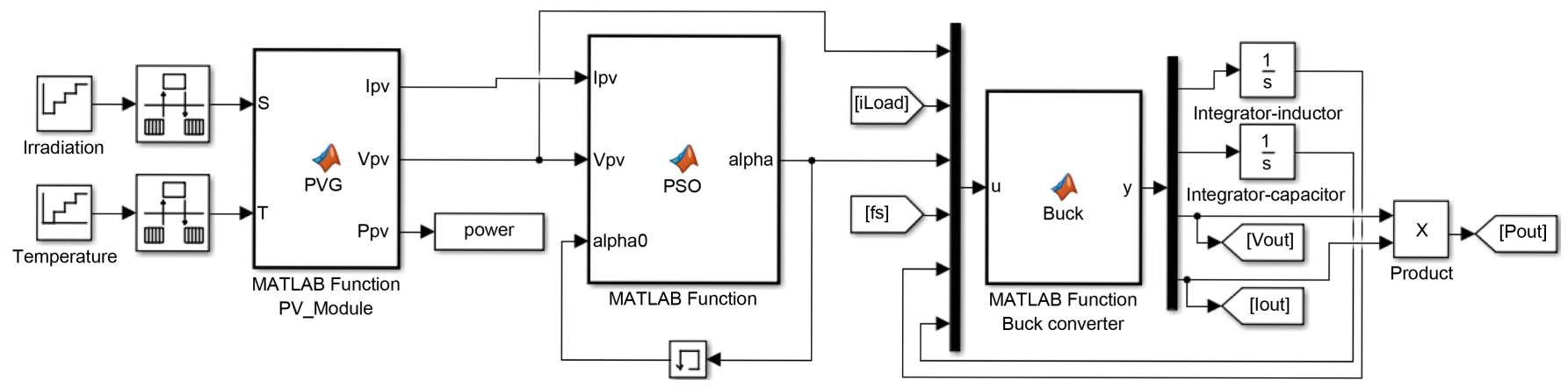

Figure 11. PV system diagram with PSO controller.

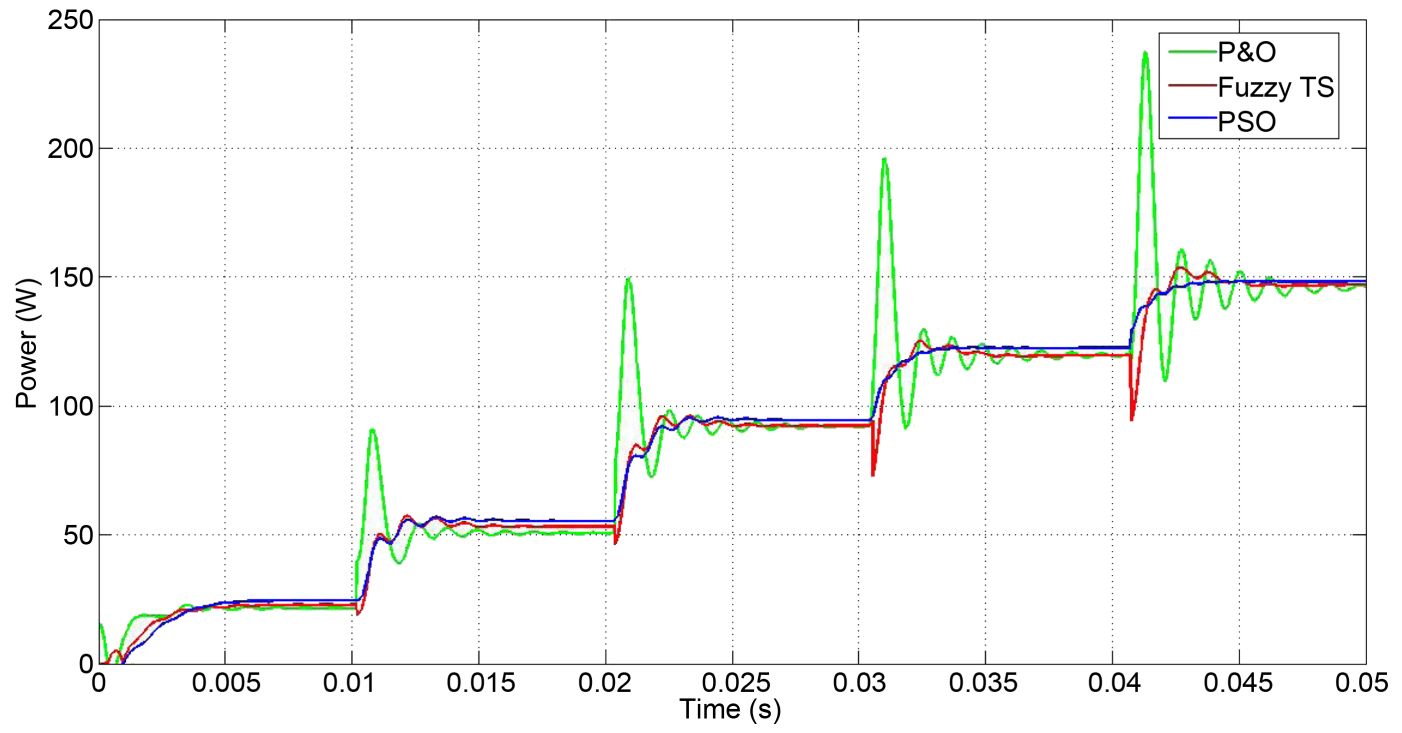

Figure 12. Comparison of convergence towards the PPM using P\&O, fuzzy TS and PSO controllers at $T=$ $25^{\circ} \mathrm{C}$ and $S$ variable. 
- In all cases, the convergence time or response time of the PSO controller is faster than the one of the "P\&O" and "Fuzzy TS" controllers.

- The "P\&O" shows oscillations around the MPP, whereas the "Fuzzy TS" and "PSO" remain quite stable.

Table 4 summarizes the simulation results about tracked power with the studied MPPT controllers for different Irradiations. It is clear that the power generated when using the PSO technique was greater than $98 \%$ under all test conditions.

\subsubsection{System Behavior near the MPP under the "PSO" Controller}

In this section, we evaluate the efficiency of the PSO controller by presenting its convergence speed and its stability vis-à-vis the MPP at the level of $\mathrm{P}-\mathrm{V}$ characteristics provided by the PV panel constructor type BPSX 150S. To evaluate the PSO controller, Figures 13-16 sum up the results of the simulations carried out concerning the P-V characteristics.

Figure 13 and Figure 14 denote the P-V characteristics of the PV panel at constant temperature of $25^{\circ} \mathrm{C}$ with varying solar irradiation.

Table 4. Tracked power under various irridation $S$ values.

\begin{tabular}{cccc}
\hline & \multicolumn{3}{c}{ Tracked Power $(\mathrm{W})$} \\
\cline { 2 - 4 } Irradiation $\left(\mathrm{W} / \mathrm{m}^{2}\right)$ & P\&O & Fuzzy_TS & PSO \\
\hline 200 & 21.45 & 22.83 & 24.46 \\
400 & 52.67 & 53.63 & 55.67 \\
600 & 102.59 & 94.44 & 95.92 \\
800 & 122.05 & 119.97 & 122.81 \\
1000 & 146.29 & 147.11 & 148.46 \\
\hline
\end{tabular}

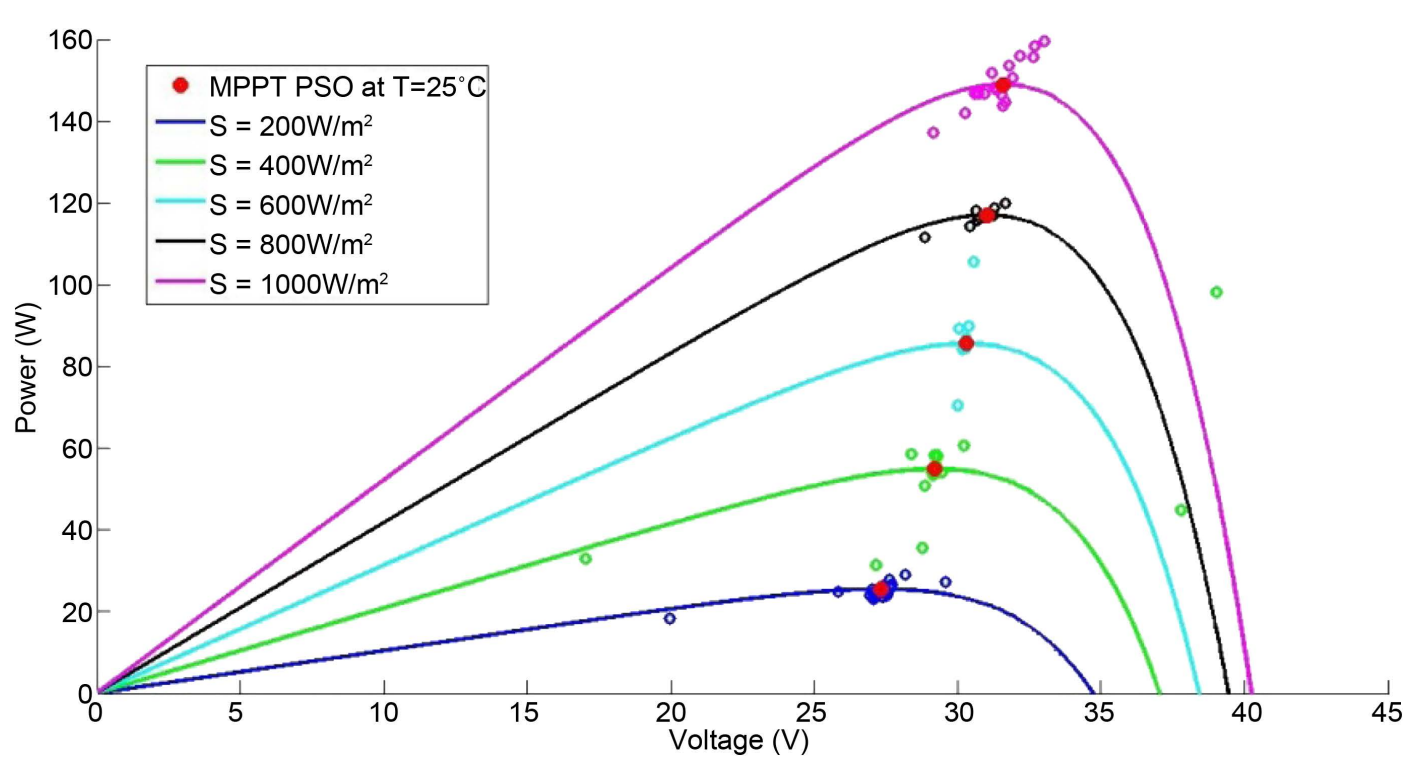

Figure 13. Convergence towards the PPM using PSO controller at $T=25^{\circ} \mathrm{C}$ and $S$ variable. 


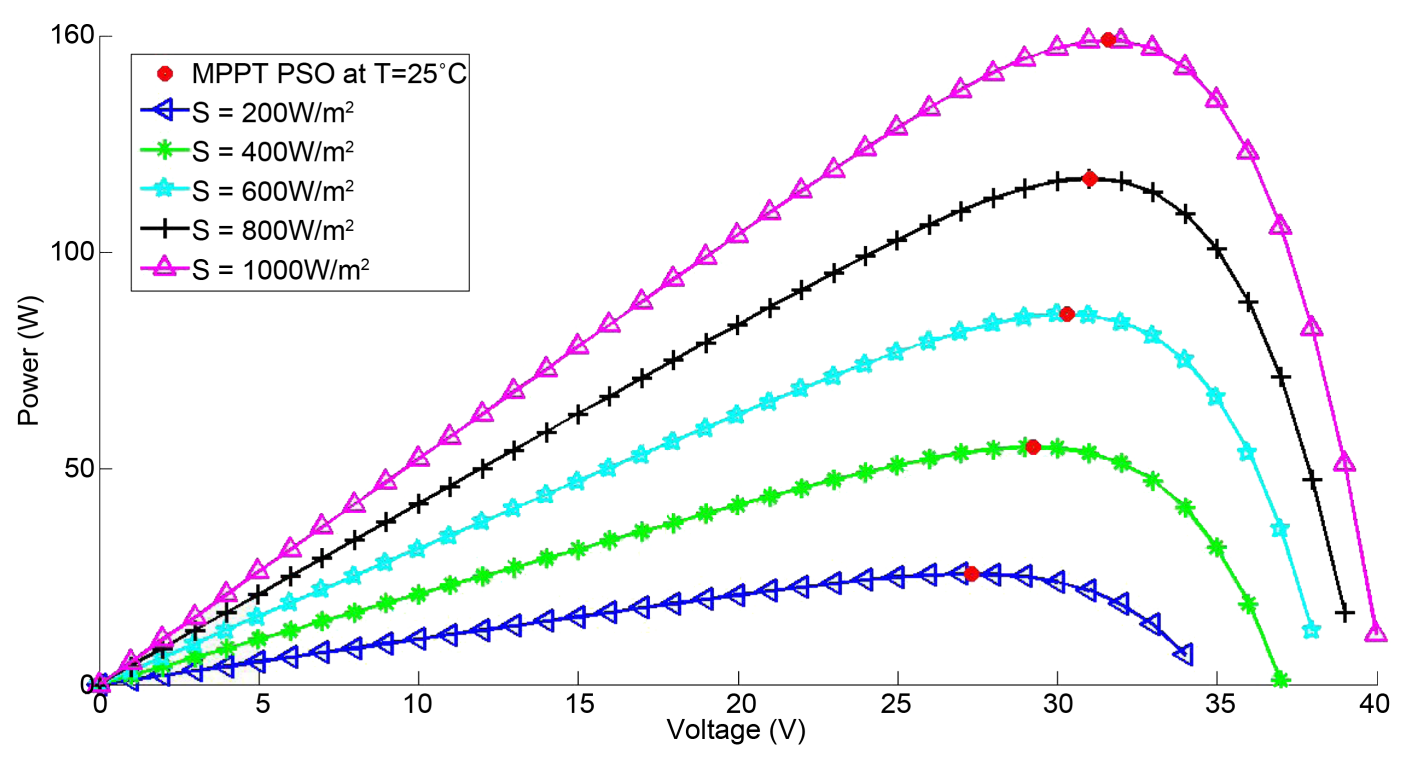

Figure 14. The PPM using PSO controller at $T=25^{\circ} \mathrm{C}$ and $S$ variable.

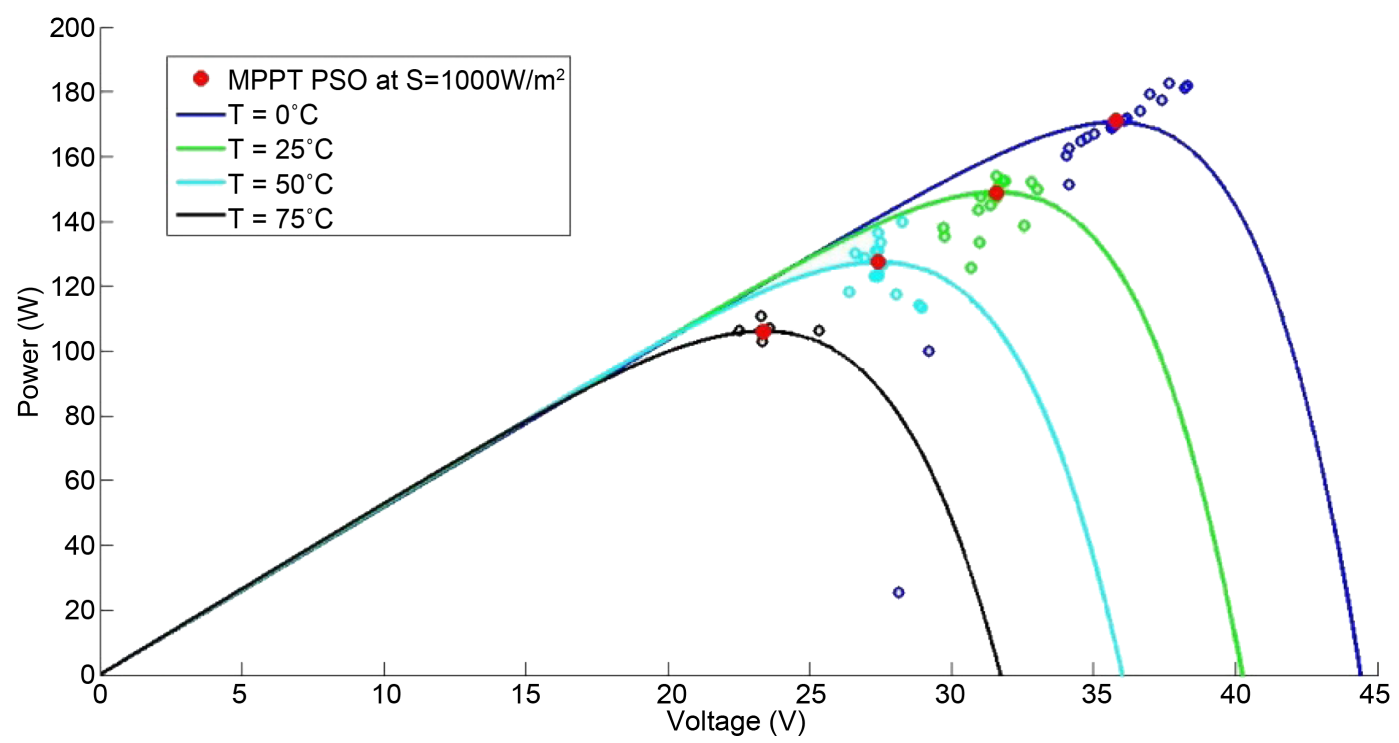

Figure 15. Convergence towards the PPM using PSO controller at $S=1000 \mathrm{~W} / \mathrm{m}^{2}$ and $T$ variable.

Figure 15 and Figure 16 show the P-V characteristics of the PV panel at constant irradiation of $1000 \mathrm{~W} / \mathrm{m}^{2}$ with various values of temperature.

\subsection{Performance Criteria of MPPT Controllers}

In order to evaluate the performances of the three types of the studied controllers theoretically and experimentally, we are interested in this section to compare two performance criteria.

- The efficiency criterion $\eta M P P T$ of a MPPT controller defined by:

$$
\eta M P P T(\%)=\frac{P p v}{P m p p} \times 100 .
$$


With:

- Pm: measured power generated by the PV panel with MPPT.

- Pmpp: maximum power generated in the same conditions of temperature and irradiation without MPPT.

- The Integral of the Squared Error (ISE):

In general, the objective of a controller is to minimize the difference between the system output and a value of a desired order. This difference may be due to either a change of order or perturbations in the system.

After considering these notes, we define the Integral of the Squared Error (ISE) by:

$$
I S E=\int_{0}^{t}[e(t)]^{2} \mathrm{~d} t
$$

where

$$
e(t)=\frac{\Delta P p v}{\Delta V p v}
$$

is the power variation in comparison to the PV panel voltage variation. $e(t)$ is the error of the first input $E$ of the fuzzy controller. The value of $e(t)$ shows that the working point for a load used at time $t$ goes to either the right or left side of the MPP on the P-V curve. The ISE criterion is evaluated in the interval $[0, t]$.

In our research, for the three studied MPPT controllers, Table 5 sums up the calculation results of the $\eta M P P T$ performance and the ISE criterion.

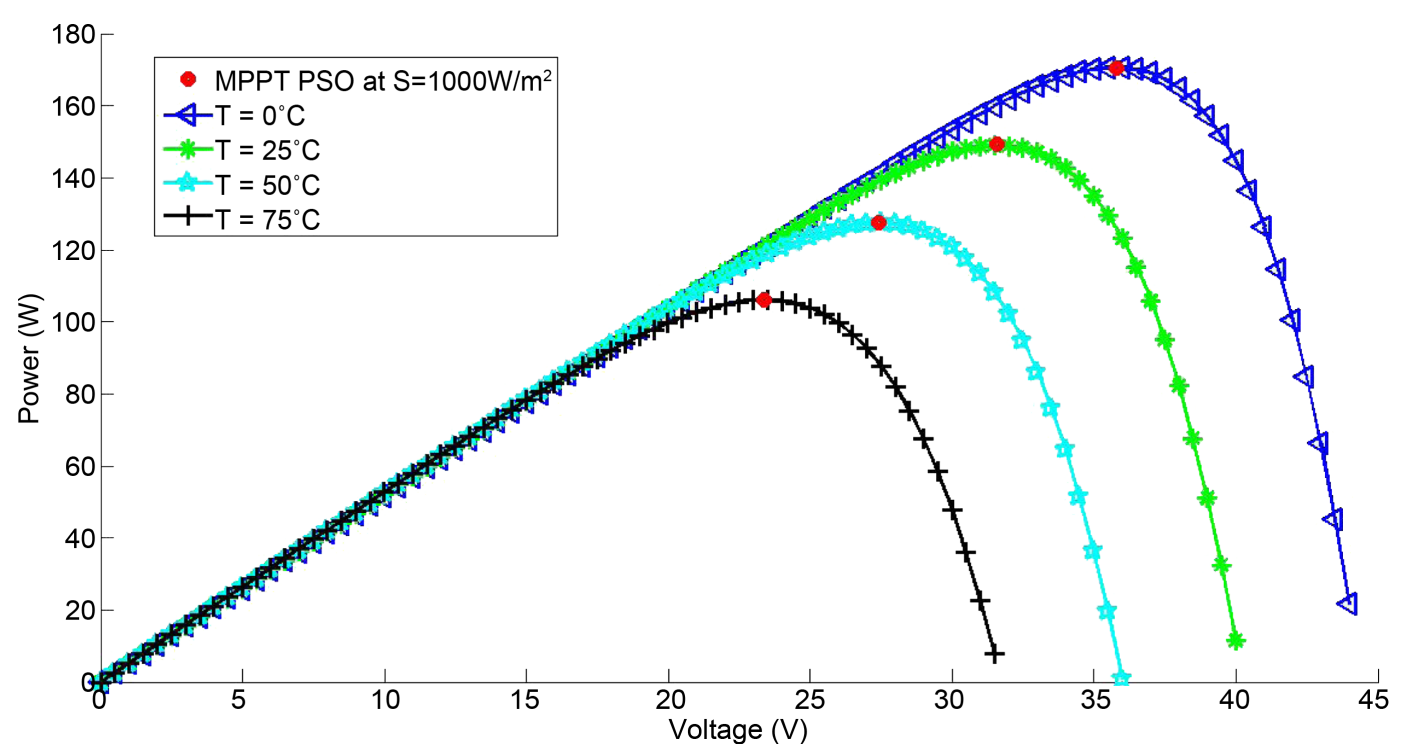

Figure 16. The PPM using PSO controller at $S=1000 \mathrm{~W} / \mathrm{m}^{2}$ and $T$ variable.

Table 5. Performance criteria of MPPT controller.

\begin{tabular}{cccc}
\hline Parameters & PSO & Fuzzy TS & P\&O \\
\hline$\eta M P P T$ & 99.30 & 99.04 & 97.03 \\
ISE.10-6 & 0.199 & 0.204 & 7.261 \\
\hline
\end{tabular}


According to the definitions above, the $\eta M P P T$ and ISE criteria, we note that the higher $\eta M P P T$ and lower ISE, the more efficient and faster MPPT.

The results we have obtained show that the use of the MPPT controller considerably and efficiently improves the performance of the PV plants. The comparison made between these three types of controllers confirm that the use of the PSO controller enables to not only minimize the ISE, which reduces the response time of the controller, but also improve the MPPT controller performance $\eta M P P T$, which aims at diminishing the fluctuations of the transient mode. This increases the efficiency of the MPPT controller type PSO and definitely ensures the improvement of stability around the MPP.

\subsection{Performance Comments}

On one side, we have classical MPPT technique such as P\&O and Fuzzy with their advantages and disadvantages.

Indeed, the Perturb and Observe technique is commonly used for MPPT and is actually widely deployed throughout industry as it is told to be simple, flexible and robust. However, $\mathrm{P} \& \mathrm{O}$ method exhibit a trade-off between tracking speed and tracking accuracy. It is due to the presence of an intrinsic trade-off in choosing perturbation frequency and step size. Also, there is a problem about the variation value around MPP. The $\mathrm{P} \& \mathrm{O}$ technique operates as a random system. The system does not know the right value of duty cycle that reaches the MPP until it varies the value of duty cycle to find the right value on that time. Therefore, it must spend time for this step and it causes wasting time.

Fuzzy based methods have strong adaptability and robustness in solving the MPPT problems in the photovoltaic system, which including a large number of uncertain factors effectively. However, in application, general fuzzy control method depends on prior knowledge to set control rules, membership functions, and relevant control parameters, which is difficult to meet real-time control requirements of photovoltaic system when the outer environment changes greatly.

As presided, each tracking algorithms have their own advantages and disadvantages. However, the traditional MPPT method often falls into local maximum value, rather than the global maximum which leads to the failure of tracking.

On the other side, PSO seems to us as a good alternative as it is a simple technique, easy to implement and as shown by simulations outperform classical technique in terms of accuracy.

\section{Conclusion}

In this article, we have studied and analyzed the running of a PV system, modeled and simulated under Matlab/Simulink, whose load is adapted by a buck converter. The regulation is ensured by three types of MPPT controllers: the classic controller "Perturb and Observe", a type Takagi-Sugeno controller deriving from fuzzy artificial intelligence and the last one is an optimization algorithm PSO. Simulation results show that our optimized PSO technique reaches the maximum power point in a shorter time with 
accurate maximum power. The analysis of merits of each technique in terms of maximum power point tracking is the main contribution of our paper. By analyzing the simulation results, it can be obtained that the PSO algorithm has advantages of high convergence speed, high precision and can accurately track the real maximum power comparing with traditional method.

\section{References}

[1] Rekioua, D. and Matagne, E. (2012) Optimisation of Photovoltaic Power Systems, Modelization, Simulation and Control. Springer. http://dx.doi.org/10.1007/978-1-4471-2403-0

[2] Enrique, J.M., Duran, E., Sidrach, M. and Andujar, J.M. (2005) A New Approach to Obtain I-V and P-V Curves of PV Panels by Using DC-DC Converters. Conference Record of the 31 st IEEE Photovoltaic Specialists Conference, Lake buena Vista, FL, 37 January 2005, 1769-1772.

[3] Rawoof, R., Balasubramanian, R. and Muthukrishnan, N.M. (2015) Modeling and Simulation of $100 \mathrm{kWp}$ Grid-Connected Photovoltaic Power System. Conference on Power, Control, Communication and Computational Technologies for Sustainable Growth (PCCCTSG), Kurnool, 11-12 December 2015, 15-20.

[4] Pradeep Kumar Yadav, A., Thirumaliah, S. and Haritha, G. (2012) Comparison of MPPT Algorithms for DC-DC Converters Based PV Systems. International Journal of Advanced Research in Electrical, Electronics and Instrumentation Engineering, 1, 18-23.

[5] Al-Diab, A. and Sourkounis, C. (2010) Variable Step Size P\&O MPPT Algorithm for PV Systems. 12th International Conference on Optimization of Electrical and Electronic Equipment (OPTIM), Brasov, 20-22 May 2010, INSPEC Accession Number: 11431599. http://dx.doi.org/10.1109/OPTIM.2010.5510441

[6] Zainudin, H.N. and Mekhilef, S. (2010) Comparison Study of Maximum Power Point Tracker Techniques for PV Systems. Proceedings of the 14th International Middle East Power Systems Conference (MEPCON 10), Cairo University, Egypt, 19-21 December 2010, 750-755.

[7] Farhat, M. and Sbita, L. (2011) Advanced Fuzzy MPPT Control Algorithm for Photovoltaic Systems. Science Academy Transactions on Renewable Energy Systems Engineering and Technology, 1, 29-36.

[8] Ajaamoum, M., Kourchi, M., Alaoui, R. and Bouhouch, L. (2013) Fuzzy Controller to Extract the Maximum Power of a Photovoltaic System. IEEE International Renewable and Sustainable Energy Conference (IRSEC), Ouarzazate, 7-9 March 2013, 141-146. http://dx.doi.org/10.1109/IRSEC.2013.6529657

[9] Oubah, R., Benzaouia, A. and El Hajjaji, A. (2015) Simulation and Control of Takagi-Sugeno Uncertain Model of Buck Converter by Linear Programming. International Conference on Microelectronics (ICM), Casablanca, 20-23 December 2015, INSPEC Accession Number: 15886305. http://dx.doi.org/10.1109/icm.2015.7438040

[10] Abid, H., Tadeo, F. and Souissi, M. (2012) Maximum Power Point Tracking for Photovoltaic Panel based on T-S Fuzzy Systems. International Journal of Computer Applications, 44, 50-58.

[11] Mule, S., Hardas, R. and Kulkarni, N.R. (2016) P\&O, IncCon and Fuzzy Logic Implemented MPPT Scheme for PV Systems Using PIC18F452. International Conference on Wireless Communications, Signal Processing and Networking (WiSPNET), Chennai, 23-25 March 2016, INSPEC Accession Number: 16304237. http://dx.doi.org/10.1109/WiSPNET.2016.7566351 
[12] Lingeswaran, K. (2014) Microcontroller-Based MPPT Control for Standalone PV System with Sepic Converter. Middle-East Journal of Scientific Research, 8, 945-950.

[13] Harrabi, N., Souissi, M., Aitouche, A. and Chaabane, M. (2016) MPPT Algorithm for Wind Energy Generation System Using T-S Fuzzy Modeling. 5th International Conference on Systems and Control (ICSC), Marrakech, 25-27 May 2016, INSPEC Accession Number: 16140156.

[14] Mayatake, M., Veerachary, M., Toriumi, F., et al. (2011) Maximum Power Point Tracking of Multiple Photovoltaic Arrays: A Particle Swarm Optimization Approach. IEEE Transactions on Aerospace and Electronic Systems, 47, 367-380. http://dx.doi.org/10.1109/TAES.2011.5705681

[15] Ishaque, K., Salam, Z., Amjad, M., et al. (2012) An Improved Particle Swarm Optimization (PSO)-Based MPPT for PV with Reduced Steady-State Oscillation. IEEE Transactions on Power Electronics, 27, 3627-3638. http://dx.doi.org/10.1109/TPEL.2012.2185713

[16] Piegari, L. and Rizzo, R. (2010) Adaptive Perturb and Observe Algorithm for Photovoltaic Maximum Power Point Tracking. Renew Power Generation IET, 4, 317-328.

http://dx.doi.org/10.1049/iet-rpg.2009.0006

[17] Takagi, T. and Sugeno, M. (1985) Fuzzy Identification of Systems and Its Application to Modeling and Control. IEEE Transactions on Systems, Man, and Cybernetics, SMC-15, 116-132. http://dx.doi.org/10.1109/TSMC.1985.6313399

Submit or recommend next manuscript to SCIRP and we will provide best service for you:

Accepting pre-submission inquiries through Email, Facebook, LinkedIn, Twitter, etc.

A wide selection of journals (inclusive of 9 subjects, more than 200 journals)

Providing 24-hour high-quality service

User-friendly online submission system

Fair and swift peer-review system

Efficient typesetting and proofreading procedure

Display of the result of downloads and visits, as well as the number of cited articles

Maximum dissemination of your research work

Submit your manuscript at: http://papersubmission.scirp.org/

Or contact epe@scirp.org 